\title{
A comparison of postoperative refractive results with and without intraocular lens power calculation
}

\author{
S M THOMPSON AND V MOHAN-ROBERTS
}

From the Eye Department of Sandwell District General Hospital, Lyndon, West Bromwich, West Midlands B71 4HJ

SUMMARY Sixty-five patients underwent intracapsular cataract extraction with implantation of Binkhorst iris-clip intraocular lenses (IOLs). For 31 patients the IOL was of a standard power. Thirty-four patients had axial length measurement and keratometry preoperatively, and IOLs calculated to produce emmetropia or 1 dioptre of myopia were implanted. There was no significant difference in the range of postoperative refractive results between the two groups.

The insertion of an intraocular lens (IOL) after cataract extraction has become widespread practice. When surgeons have mastered the basic techniques, they naturally attempt various refinements. One of these is the measurement of the eye preoperatively so that a lens of appropriate dioptric power may be inserted.

Since Binkhorst' $\mathrm{s}^{1}$ and Colenbrander's ${ }^{2}$ descriptions of a method of calculating IOL power to minimise aniseikonia, many workers have tailored IOL power by measuring corneal curvature and the axial length of the eye, and reported their postoperative results. However, few surgeons have compared the refractive results of a group of patients whose IOL powers had been calculated with a group receiving IOLs of standard power. We report such a series.

\section{Patients and methods}

Sixty-five patients underwent intracapsular cataract extraction and insertion of a Binkhorst iris-clip intraocular lens by a single surgeon (VMR) using a standard procedure. After general anaesthesia five virgin silk sutures were placed in a corneoscleral incision. The cataract was removed with a cryoprobe, and a single $10 / 0$ nylon iris suture placed to anchor the upper loop of the intraocular lens.

One group of 31 patients ( 32 eyes) received a standard power IOL of 19 dioptres in air, \pm 0.5 dioptre depending on availability. This group com-

Correspondence to Mr S M Thompson, FRCS. prised 21 women and 10 men, with a mean age of 68.9 years (range $50-86$ years).

The second group of 34 patients ( 35 eyes) underwent preoperative ultrasonic measurement of the axial length of the eye with a Radionics EchoOculometer 3000 . This system uses an applanationtype transducer. The corneal curvature of each eye was measured with a Haag-Streit keratometer. Using the Binkhorst formula, a Texas Instruments $58 \mathrm{C} / 59$ programmable calculator worked out the IOL powers required to produce emmetropia, and 1 dioptre of myopia, in each eye. Of these the lens with the power nearer to the standard $\pm 19 \mathrm{D}$ in air was selected for implantation. Fourteen patients received lenses designed to produce emmetropia, and 20 patients (21 eyes) received lenses calculated to produce one dioptre of myopia.

The 'measured' group comprised 26 women and 8 men, of mean age $68 \cdot 8$ years (range $57-86$ years). The patients were allocated to either group by the surgeon on a random basis, but no formal randomisation procedure was followed. One patient was excluded because axial length measurement revealed high myopia.

All patients underwent refraction six to 12 weeks after surgery and were prescribed glasses if necessary. Two patients (one 'measured' and one 'unmeasured') were not included in the series because their IOLs were removed soon after cataract surgery. One developed intractable pupil block glaucoma and one corneal decompensation.

The postoperative spherical equivalent refraction was calculated for each patient. In the unmeasured 
group the difference between this and emmetropia was determined. In the measured group the difference between the postoperative refraction and the predicted refraction was determined.

\section{Results}

The powers of the intraocular lenses implanted in the measured group ranged from $16 \cdot 5$ to 24 dioptres in air. Fig. 1 shows the distribution of powers.

Visual acuity. Table 1 shows that the visual outcome for the two groups was similar. One patient in the unmeasured group had persistent cystoid macular oedema, but her corrected visual acuity remained at $6 / 12$.

Refractive error. Postoperative astigmatism was similar in the two groups; mean 1.9 D (range 0-4 D, SD $0.9 \mathrm{D}$ ) in the unmeasured group, mean $1.97 \mathrm{D}$ (range 0-6 D, SD 1.1 D) in the measured group.

Fig. 2 and 3 show the distribution of the difference between the spherical equivalent refraction and emmetropia for the unmeasured group, and between
Table 1 Postoperative corrected visual acuity

\begin{tabular}{lcc}
\hline $\begin{array}{l}\text { Corrected } \\
\text { vision }\end{array}$ & $\begin{array}{l}\text { Measured } \\
\text { group }\end{array}$ & $\begin{array}{l}\text { Unmeasured } \\
\text { group }\end{array}$ \\
\hline $6 / 5$ & 3 & 7 \\
$6 / 6$ & 17 & 16 \\
$6 / 9$ & 7 & 7 \\
$6 / 12$ & 8 & 2 \\
\hline
\end{tabular}

the spherical equivalent and predicted refraction for the measured group. In the unmeasured group $65.6 \%$ of the patients fell within $1 \mathrm{D}$ of emmetropia, $90.6 \%$ fell within $2 \mathrm{D}$, and $100 \%$ within $3 \mathrm{D}$. In the measured group $74.3 \%$ of the patients fell within $1 \mathrm{D}$ of the predicted refraction, $91.4 \%$ within $2 \mathrm{D}$, and $100 \%$ within $3 \mathrm{D}$.

A Mann-Whitney test showed that there was no significant difference between the groups $(p=0 \cdot 8)$. If the difference between spherical equivalent refraction and emmetropia is taken for both groups, there is still no significant difference between the groups (Mann-Whitney test $\mathrm{p}=0 \cdot 2$ ).
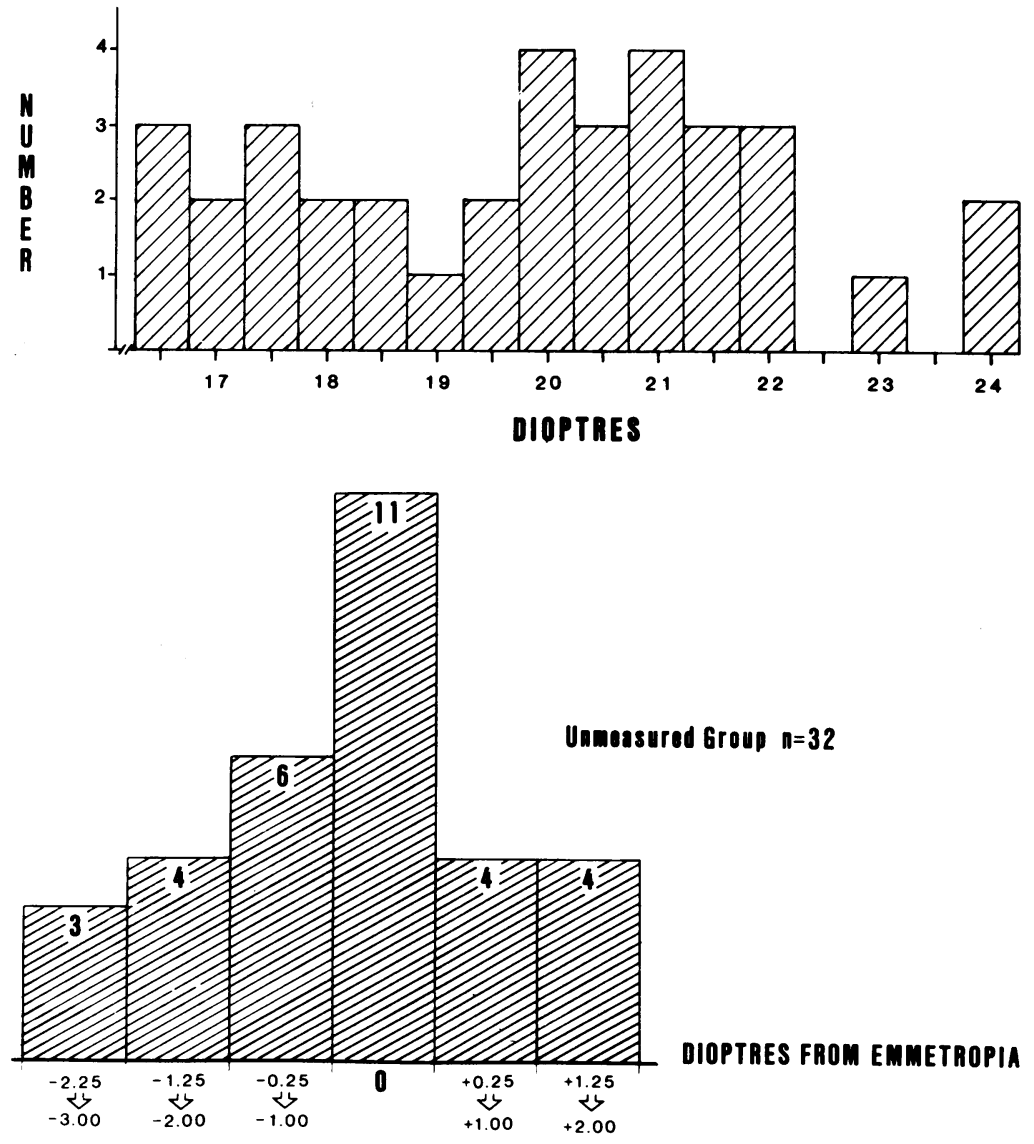

Fig. 1 Range of lenses implanted into measured group. 
Fig. 3 Difference between postoperative and predicted refraction.

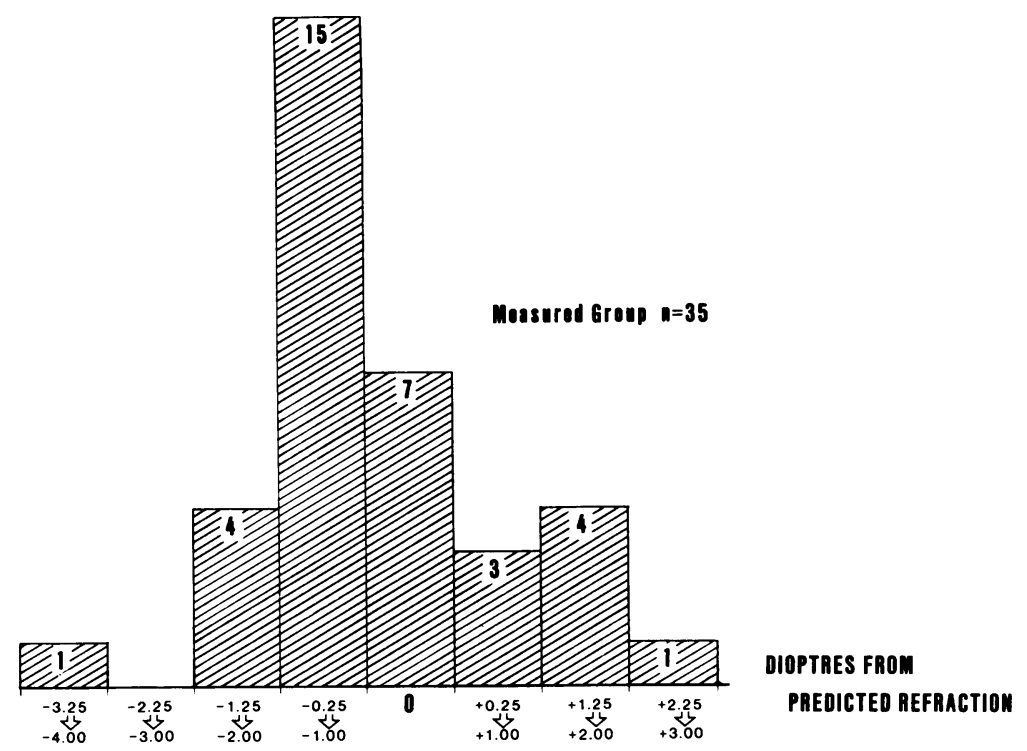

\section{Discussion}

Many workers have shown that the preoperative calculation of appropriate IOL power by measuring the corneal curvature and axial length is accurate and useful. ${ }^{3}$ In this series the accuracy of IOL measurements is similar to that of many reported series. ${ }^{4}$

The four main reasons why IOL calculations may be carried out are: (1) as a routine to achieve a desired postoperative refraction, usually emmetropia ${ }^{35-8}$; (2) to minimise anisometropia in patients with a high refractive error in the fellow noncataractous eye'; (3) as a routine to avoid unexpected high ametropia; (4) to avoid aniseikonia. ${ }^{10}$

In practice the fourth application does not seem to be widely used, but Hillman has shown that lens calculation is useful for planned ametropia in patients with a high refractive error in the fellow eye. ${ }^{9}$ However, a case has been made for routine preoperative lens calculation in all patients to achieve a desired refraction and avoid unexpected high ametropia. ${ }^{\prime \prime}$

The results of our series suggest that the use of a standard power IOL produces results as satisfactory overall as the routine calculation of IOL power. Where medical and technical resources are finite, routine lens calculation may not be indicated.

This study may be criticised on two main points. It is possible that a larger series would reveal more of a difference between the groups or some unexpectedly high refractive error in the uncalculated group.

In Hillman's series ${ }^{3} 100$ consecutive patients received standard power IOLs and 100 received calculated IOLs. The difference between postopera- tive spherical equivalent refraction and emmetropia were calculated. A Mann-Whitney test applied to these data shows a significant difference between the groups $(p=0 \cdot 02)$. However, the estimated difference of the means for these two groups was only 0.54 dioptre. This indicates that the statistical significance of the difference may be more than the clinical significance. Perhaps of more importance was the occurrence of several unexpectedly high post-operative refractive errors in the uncalculated group. For this reason we are doing a further study in which IOL power will be calculated if clinically indicated (see Percival") to avoid high ametropia.

The selection of patients for the present series was not truly random. Any unconscious selection bias would be expected to place ametropic patients in the measured group. This would reduce the difference in postoperative results between the two groups. In our study in progress half the patients without clinical indications for measuring will in fact have calculated IOLs and selection will be on a random basis.

Our thanks go to Dr Kent Woods for statistical help, Evelyn Dawes for typing the manuscript, and Alistair Rose and Mavis Rooney for preparing the illustrations.

\section{References}

1 Binkhorst CD. Power of the prepupillary pseudophakos. Br J Ophthalmol 1972; 56: 332.

2 Colenbrander MC. Calculation of the power of an iris clip lens for distant vision. Br J Ophthalmol 1973; 56: 735-40.

3 Hillman JS. The selection of intra-ocular lens power by calculation and by reference to the refraction-a clinical study. Trans Ophthalmol Soc UK 1982; 102: 495-7.

4 Hoffer KJ. Accuracy of ultrasound intra-ocular lens calculation. Arch Ophthalmol 1981; 99: 1819-23. 
5 Mabury WF, Kratz RP, Mazzollo TR, Davidson B. Posterior chamber intra-ocular lens power calculation in 441 cases. $\mathrm{J} \mathrm{Am}$ Intraocul Implant Soc 1979; 5: 349-50.

6 Kraff MC, Sanders DR, Lieberman HL. Biometric analysis of intra-ocular lens power required to produce emmetropia: results of 450 implants. J Am Intraocul Implant Soc 1978; 4: 45-7.

7 Johns GE. Clinical evaluations of the DBR A-scan unit. J Am Intraocul Implant Soc 1979; 5: 213-6.

8 Clevenger CE. Clinical prediction versus ultrasound measure- ment of IOL power. J Am Intraocul Implant Soc 1978; 4: 222-4.

9 Hillman JS. Intra-ocular lens power calculation for planned ametropia: a clinical study. Br J Ophthalmol 1983; 67: 255-8.

10 Huber C, Binkhorst C. Iseikonic lens implantation in anisometropia. J Am Intraocul Implant Soc 1979; 5: 194-8.

11 Percival P. Lens power calculation-is it necessary? Trans Ophthalmol Soc UK 1983; 103: 577-9.

Accepted for publication 11 April 1985. 